\title{
A origem do mundo: um estudo sobre o episódio cosmogônico das Metamorfoses de Ovídio
}

The beginning of the world: a study on the cosmogonic episode in Ovid's Metamorphoses

\author{
Paulo Eduardo de Barros Veiga ${ }^{1}$ \\ e-mail: pauloveiga@usp.br \\ orcid: https://orcid.org/0000-0002-1250-8237
}

DOI: https://doi.org/10.25187/codex.v811.31793

RESUMO: Ovídio (43 a. C. - 17 d. C.), poeta do período Clássico da Roma Antiga, mais precisamente da época de Augusto, escreveu por volta de 8 d. C. a obra intitulada Metamorfoses (Metamorphoseon libri), um longo poema dividido em quinze livros. Nele, de modo geral, narramse diversos mitos, com enfoque nas transformações de seres e de coisas. Mais especificamente, o Livro I conta histórias mitológicas a respeito da origem do mundo. O tema central dos versos escolhidos neste artigo é a Cosmogonia, um conjunto de mitos etiológicos que narra o princípio do universo e as transformações que o mundo sofreu para chegar à forma atual. Analisam-se os hexâmetros 5 a 20 que abrem o episódio cosmogônico a partir do Caos. Neles, observam-se as figuras que compõem a Cosmogonia, no nível discursivo, investigando, com maior ênfase, os recursos icônicos percebidos nos versos de Ovídio, em busca da significação poético-textual.

PALAVRAS-CHAVE: Ovídio; as Metamorfoses; Cosmogonia; expressividade poética; tradução

\begin{abstract}
A poet of the Classical period of Ancient Rome, more precisely from Augustan Age, Ovid (43 BC - 17 AD) wrote around 8 AD a work entitled the Metamorphoses (Metamorphoseon libri), a long poem divided into fifteen books. This book tells in general many myths about the transformation of beings and things. More specifically, Book I narrates mythological stories about the origin of the world. The main theme of the excerpt chose in this paper is the Cosmogenesis, a series of etiological myths about the principle of the universe and the transformation that the world undergone to be at its final disposition. In this paper, we analyse the hexameters numbers 5 to 20 which open the cosmogonic episode, starting from the Chaos. In this passage we observe the figures that characterize Cosmogenesis, at the level of discourse, and also examine more enfatically the iconic resources noted in Ovid's verses, seeking the textual-poetic signification.
\end{abstract}

KEYWORDS: Ovid, the Metamorphoses; Cosmogenesis; poetic expression; traduction

\footnotetext{
${ }^{1}$ Pós-doutorando pela Faculdade de Filosofia, Ciências e Letras de Ribeirão Preto, Departamento de Música, da Universidade de São Paulo, São Paulo, Brasil (USP-FFCLRP-DM). Processo nº 2018/01418-2, Fundação de Amparo à Pesquisa do Estado de São Paulo (FAPESP).
} 


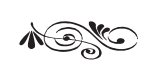

Introdução ${ }^{2}$

Públio Ovídio Nasão (Publius Ouidius Nasus) foi um poeta romano autor de várias obras, dentre as quais se destacam as Heróides (Heroidum epistolae), os Amores (Amores), a Arte de amar (Ars amatoria) e as Metamorfoses (Metamorphoseon libri), sua obra de maior extensão, constituída de 11.995 hexâmetros. O poeta nasceu no ano de 43 a. C., em Sulmona, cidade localizada atualmente em Abruzzo, que faz fronteira com o Lazio, na Itália. Sua família era da classe dos equites ${ }^{3}$ e garantiu aos filhos, no caso, Ovídio e seu irmão mais velho, o acesso à educação, mais especificamente, aos estudos de Retórica. Apesar de tentar tornar-se um político, como um senador, foi a poesia que o levou ao caminho da fama (CONTE, 1999). Nos seus últimos anos em Roma, Ovídio produziu suas duas obras principais: os Fastos e as Metamorfoses, que foram escritas concomitantemente (HOWATSON, 2005, p. 04). Diz-se que, em seguida, o imperador Augusto envia-o ao exílio, em Tomi, onde continuou a sua produção poética, com destaque à elegia.

Os hexâmetros ${ }^{4}$ em análise neste artigo são excertos retirados das Metamorfoses de Ovídio, um extenso poema, escrito entre 2 a 8 d. C. A obra é composta de quinze livros, totalizando 11.995 versos, todos hexâmetros, em que se narram várias histórias míticas relacionadas a transformações, como a história trágica de Narciso, que se transforma em flor, e a de Níobe, convertida em uma estátua que chora eternamente os filhos perdidos. Destaca-se que, devido a sua extensão, o poema é considerado o mais longo de toda a literatura latina até hoje encontrada.

\footnotetext{
${ }^{2}$ Este artigo é fruto de parte da pesquisa de Doutorado em Estudos Literários, intitulada "A Cosmogonia nas Metamorfoses de Ovídio: um estudo sobre as figuras da origem do mundo, com Tradução e Notas”, sob orientação do Prof. Dr. Márcio Thamos. O doutoramento foi concluído em 2017 na Universidade Estadual Paulista, Faculdade de Ciências e Letras de Araraquara (UNESP-FCLAr). No ano de 2020, durante o pós-doutorado, sob supervisão do Prof. Dr. Rubens Russomanno Ricciardi, pela Universidade de São Paulo, Faculdade de Filosofia, Ciências e Letras de Ribeirão Preto (USP-FFCLRP), foram feitas revisões e atualizações deste artigo, incluindo-se alguns acréscimos. Por essa razão, expresso meu agradecimento a ambas as universidades públicas - Universidade Estadual Paulista (UNESP) e Universidade de São Paulo (USP) - pelo meu acolhimento em distintos estágios acadêmicos, e, em especial, à Fundação de Amparo à Pesquisa do Estado de São Paulo, pelo apoio financeiro, que nos mantém em constante pesquisa, a favor das Ciências e das Artes no país. (Processo $\mathrm{n}^{\circ}$ 2018/01418-2, Fundação de Amparo à Pesquisa do Estado de São Paulo (FAPESP).

3 Em Latim, eques significa cavaleiro e, por extensão de sentido, a ordem dos cavaleiros. Faria afirma que "a ordem dos cavaleiros abrangia, a princípio, os homens que serviam na cavalaria; mais tarde passou a designar uma categoria de certos cidadãos que pagavam determinado censo e possuíam certos direitos” (FARIA, 1967). Ovídio, portanto, nasceu em uma família de posição econômica estável, pertencente à aristocracia.

${ }^{4}$ O hexâmetro datílico é um verso compostos por seis pés métricos. Os quatro primeiros pés podem ser dátilos $\left({ }^{-} \smile\right)$ ou espondeus $\left(^{--}\right)$. O quinto é sempre um dátilo, por isso o seu nome. O sexto pé varia entre um troqueu $\left(^{-}-\right)$ou um espondeu.
} 
No Livro I das Metamorfoses, o tema principal é a Cosmogonia, um conjunto de mitos que procura explicar a origem do universo, como a separação dos elementos cósmicos e as transformações das Idades do mundo. Em outras palavras, a Cosmogonia ou Cosmogênese é uma reunião de mitos que se ocupam em explicar a origem do universo e dos primeiros seres. Este artigo analisa mais especificamente os hexâmetros 5 a 20 que contam a origem do mundo, a partir do Caos.

\section{A origem do mundo (hex. $5-20)$}

Esta seção apresenta os hexâmetros de número 5 a 20 que tratam do tema da "origem do mundo", mais especificamente da origem dos elementos, ainda discordes, a partir do Caos. Observaram-se, com mais ênfase, as escolhas figurativas que o poeta fez para a construção desse tema.

Abaixo, dispõem-se o texto latino em paralelo com a tradução do poeta português Bocage (1765-1805), para que o leitor tenha, como experiência poética de leitura, uma dimensão do que seria o equivalente da obra ovidiana em língua portuguesa e, ainda mais, em versos decassílabos, haja vista os efeitos expressivos do texto original. A esse conjunto segue uma tradução em prosa do mesmo excerto, com notas de referências mitológicas:

Ante mare et terras et, quod tegit omnia, caelum

Vnus erat toto naturae uultus in orbe,

Quem dixere chaos: rudis indigestaque moles

Nec quicquam nisi pondus iners congestaque eodem

Non bene iunctarum discordia semina rerum.

Nullus adhuc mundo praebebat lumina Titan,

Nec noua crescendo reparabat cornua Phoebe,

Nec circumfuso pendebat in aere tellus

Ponderibus librata suis, nec bracchia longo

Margine terrarum porrexerat Amphitrite.

Vtque erat et tellus illic et pontus et aer,

Sic erat instabilis tellus, innabilis unda,

Lucis egens aer; nulli sua forma manebat

Obstabatque aliis aliud, quia corpore in uno

Frigida pugnabant calidis, umentia siccis, Mollia cum duris, sine pondere habentia pondus

(Ov. Met., I.5-20)
Antes do mar, da Terra, e céu que os cobre Não tinha mais que um rosto a Natureza:

Este era o Caos, massa indigesta, rude,

E consistente só num peso inerte.

Das coisas não bem juntas as discordes, Priscas sementes em montão jaziam;

O Sol não dava claridade ao mundo,

Nem crescendo outra vez se reparavam As pontas de marfim da nova Lua.

Não pendias, ó Terra, dentre os ares,

$\mathrm{Na}$ gravidade tua equilibrada

Nem pelas grandes margens Anfitrite

Os espumosos braços dilatava.

Ar, e pélago, e Terra estavam mistos:

As águas eram pois inavegáveis,

Os ares negros, movediça a Terra.

Forma nenhuma em nenhum corpo havia,

E nele uma coisa a outra obstava,

Que em cada qual dos embriões enormes

Pugnavam frio, e quente, úmido, e seco,

Mole, e duro, o que é leve, e o que é pesado.

(OVÍDIO, 2000, p. 35-36) 


\section{Tradução em prosa:}

Antes do mar e das terras e do céu, que cobre tudo, o rosto da natureza era um em todo orbe, chamaram-no Caos: massa informe e desordenada ${ }^{5}$. Nada havia, senão um peso inerte e, amontoadas nele, desunidas sementes de coisas não bem conexas ${ }^{6}$. Ainda nenhum Titã ${ }^{7}$ dava luz ao mundo, nem Febe ${ }^{8}$ nova, crescendo, renovava os cornos, nem a terra pendia no ar que a envolve, com seus próprios pesos equilibrada, nem Anfitrite ${ }^{9}$ estendera os braços, pela extensa margem das terras. Ainda que houvesse ali terra e oceano e ar, a terra era ainda instável, as ondas inábeis, o ar desprovido de luz. A forma de nada permanecia, e uma coisa fazia obstáculo a outra, porque, em um mesmo corpo, as frias temperaturas lutavam contra as quentes, as coisas úmidas, com as secas, as moles, com as duras, as com peso, com as sem peso ${ }^{10}$.

Ovídio inicia o episódio cosmogônico relatando a origem do mundo a partir do Caos, massa inerte composta por todos os elementos, sem forma e distinção. Trata-se, portanto, de um período anterior à separação dos quatro elementos fundamentais que constituem o universo, quais sejam a água, o ar, a terra e o fogo, e que estão, ainda, misturados.

O primeiro verso destaca os três elementos primordiais da formação do mundo, enumerandoos: o mar, a terra e o céu, futuros "genitores" de todos os outros. Nesse sentido, o Caos seria, portanto,

\footnotetext{
${ }^{5}$ Caos, segundo a mitologia romana, é uma entidade primitiva, senão a primeira a existir. O Caos representa o mundo ainda não distinto, sem a separação dos quatro elementos fundamentais, quais sejam, água, ar, fogo e terra. Essa enorme massa, sem forma e vida, portanto, contém toda a matéria que, ao ser organizada, resultaria nas coisas e nos seres. Sobre o Caos, Commelin afirma que seria "o estado primordial, primitivo do mundo" (COMMELIN, [19--], p. 18). Assim, ele "era, segundo os poetas, uma matéria que existia desde tempos imemoriais, sob uma forma vaga, indefinível, indescritível, na qual se confundiam os princípios de todos os seres particulares." (ibid.). O Caos seria, logo, a mistura das substâncias ainda não enformadas. Evite-se, portanto, a ideia habitual de Caos, como confusão ou perturbação; mas indistinção e inércia. Em outras palavras, é o estado inerte e indistinto dos elementos primordiais.

${ }^{6}$ Essa imagem, a de uma massa inativa, espécie de útero que guarda sementes, ainda sem organização, configura o estado

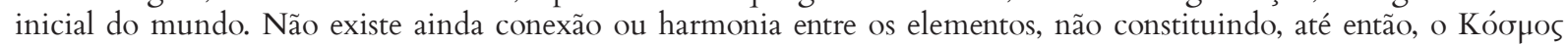
(Kósmos), um estado já ordenado das coisas. Nos hexâmetros seguintes, de número 21 a 75, o narrador ovidiano trata do processo de organização dos elementos fundamentais, quais sejam, ar, água, terra e fogo, e do surgimento dos animais. $\mathrm{O}$

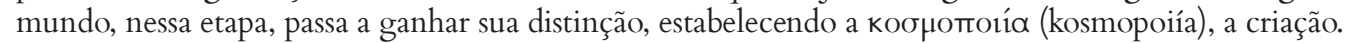

7 O Sol, responsável por dar luz ao mundo, é filho do Titã Hiperião, cujos pais são Uranos e Terra. Por essa razão, o sol é chamado de Titã (NAGEOTTE, [s.d.], p. 02).

${ }^{8}$ Em oposição ao Sol, Febe corresponde à Lua. Em relação aos diversos nomes associados tanto à Lua, quanto ao Sol, Commelin destaca que "assim como os poetas confundem muitas vezes Apolo, Febo e o Sol na mesma personalidade, também assim identificaram frequentemente Ártemis e Selene, Diana e a Lua” (COMMELIN, [19--], p. 71). Em relação à passagem, acrescenta-se o comentário de Anderson: "Ovid uses Phoebe and Phoebus for Moon and Sun and also for Diana and Apollo, originally two quite different pairs" (OVID, 1998, p. 154). [Ovídio emprega Febe e Febo respectivamente para a Lua e o Sol; bem como para Diana e Apolo, originalmente dois pares bem distintos.]

9 Anfitrite, filha de Nereu, é rainha do mar, casada com Netuno, senhor das águas. Essa deusa, logo, personifica o mar. Anderson, a respeito dessa passagem, comenta que "Ovid juxtaposes a poetic Picture of the sea. The "arms" here will combine with verb and subject to create an image of a feminine embrace" (OVID, 1998, p. 154). [Ovídio justapõe uma Imagem poética do mar. Os "braços", aqui, combinar-se-ão com o verbo e o sujeito para criar uma imagem de um abraço feminino].

${ }^{10}$ Em estado de caos, portanto, tudo se misturava, isto é, os opostos estavam misturados, formando uma substância complexa.
} 
o período anterior à organização desses elementos, em que tudo se encontra amalgamado na mesma substância inativa.

O único rosto da natureza, portanto, era o Caos, ou seja, a mistura de tudo. Assim, o mundo inicial configura-se como um estado de indistinção das coisas, em que as "sementes" - isto é, substâncias que, ao separar-se do todo, têm o potencial de tomar forma e corpo - ainda se encontram indistintas e sem lugar.

Portanto, a figura do Caos, haja vista a sua descrição como um amálgama ou uma substância inativa (pondus iners), com sementes, representa um estado universal de latência, potencialidade ou complexidade, em que há uma grande mistura de tudo que possa vir a ser. O Caos precede a triagem de todos os elementos, permanecendo como um estado de coisas sem acontecimento.

O conceito de um corpo dotado de potência (semina) tem sua imbricação filosófica na obra De rerum natura de Lucrécio (96 - 55 a. C.), um poeta epicurista anterior a Ovídio. A semente é, pois, uma substância complexa, dotada da capacidade de gerar, sendo um princípio básico do funcionamento do mundo, mais especificamente do mundo físico. Lucrécio, assim, estabelece uma doutrina epicurista sobre o universo físico. Sendo matéria, tudo surge dos corpos primordiais, as sementes:

(...) vou começar a expor-te a essência do céu e dos deuses, e revelar-te-ei os princípios das coisas, donde as cria a natureza e as faz crescer e as alimenta, e para onde de novo as leva a mesma natureza, já exaustas; a estes princípios, na exposição da doutrina, damos nós habitualmente o nome de matéria, de corpos geradores e de sementes das coisas; e até lhes chamamos corpos primordiais, porque deles, como princípio, tudo surge (LUCRÉCIO, Da Natureza, I, 53-60) ${ }^{11}$.

Ademais, em relação ao nascimento das coisas, o epicurista sugere que, já que não é possível tudo nascer de tudo, é pertinente haver um corpo primordial, em estado de potência, qual seja, a semente. "Realmente, se fosse possível nascer do nada, tudo poderia nascer de tudo, e coisa alguma teria necessidade de semente" (LUCRÉCIO, Da Natureza, I, 160) ${ }^{12}$. O Caos seria, logo, a reunião desconexa de sementes, constituindo-se no mais complexo amálgama de corpos primordiais.

Acresce-se que, nas Metamorfoses, há uma rede de correspondências com outras obras anteriores a Ovídio, estabelecendo com o poema um fator de unidade. Por exemplo, duas obras exerceram influência sobre a narrativa das Metamorfoses e o seu desencadeamento: "Panegírico de Messala”, de Tibulo, e a Sexta Bucólica, de Virgílio (SANTOS, [s. d., n. p.]). Ademais, a cosmogonia do Livro I das Metamorfoses dialoga com a física de Empédocles (século V a. C.), entre outras possíveis

\footnotetext{
${ }^{11}$ Tradução de Agostinho da Silva (In: LUCRÉCIO. Da natureza. São Paulo: Abril Cultural, 1985, p. 31-32).

12 Tradução de Agostinho da Silva (In: LUCRÉCIO. Da natureza. São Paulo: Abril Cultural, 1985, p. 33).
} 
referências, como Parmênides (séculos VI-V a. C.). Logo após o prólogo, praticamente termo a termo, os versos 5 e 6 da obra ovidiana foram inspirados nos versos 496 e 497 do Livro I das Argonáuticas de Apolônio de Rodes, uma passagem narrada por Orfeu. A Cosmogonia de Ovídio, assim, está eivada da noção cosmogônica empedocliana, que também se encontra em Apolônio ( $\mathrm{Arg}$. I, 498), ao apontar "a luta entre os elementos como fator de diferenciação, enquanto Ovídio faz intervir uma divindade anônima ao lado da natureza, para instaurar a ordem universal, a harmonia” (SANTOS, [s. d., n. p.]). Além da inspiração empedocliana, órfica, apoloniana e lucreciana, pode-se dizer que Ovídio (I, 21) traz a voz de Horácio, quando menciona o deus, um demiurgo, que separa as diversas partes do mundo (SANTOS, [s. d., n. p.]).

No Caos, em suma, ainda não foram dados função, lugar e nome aos seres e às coisas. Ele se configura, pois, como uma massa informe em que tudo está latente, tudo se mistura. O Caos, por certo, é uma situação de amálgama, que, segundo Zilberberg, a partir da definição do dicionário francês Micro-Robert, é a "mistura de elementos que não combinam bem" (ZILBERBERG, 2004, p. 85). De fato, em Ovídio, os elementos "lutam” entre si (pugnabant), pois não há, ainda, lugar. Ou seja, a triagem das substâncias ainda não foi feita.

Segundo o dicionário Houaiss, mistura é um "conjunto, composto ou produto resultante de coisas misturadas; mescla, misto, amálgama” (HOUAISS, 2001, s. v.). O dicionário ainda sugere: uma "reunião de coisas diversas e/ou opostas; misto, mescla (...), 'o que é composto de vários elementos ou resulta da junção de elementos diversos" (ibid.). Já a triagem, segundo o mesmo dicionário, seria a ação de separar, de selecionar ou escolher com base em algum critério definido (HOUAISS, 2001, s. v.).

A mistura, assim, torna-se a operação fundamental que constitui o Caos, cuja transformação ocorre mediante o processo de triagem ${ }^{13}$, verificada no episódio seguinte, em que os quatro elementos fundamentais - ar, terra, fogo e água - separam-se. Tria-se com base na densidade ou no peso dos elementos, como critério de seleção. O Caos, no entanto, é um estado anterior, de mistura, mais especificamente, de amálgama.

Além da ideia de mistura, um outro ponto relevante na construção da figura do Caos é, em Ovídio, a sua descrição por meio da negação. Isto é, Ovídio estabelece uma "poética da negação" para configurar o Caos. O poeta consegue descrever visualmente o início do universo por meio de um artifício embasado na negação e em sua repetição, mediante a anáfora. Ou seja, ele caracteriza o momento primeiro do mundo negando a existência de deuses e seres e a ordem dos elementos e

\footnotetext{
${ }_{13}$ Mistura e Triagem, em suma, são conceitos advindos dos estudos de Zilberberg (1988; 2004; 2011). Sugere-se, nesta nota, que ambos os termos podem ajudar a compreender o fenômeno cosmogônico na obra ovidiana, em se tratando principalmente do Caos e de sua dissolução. De modo sucinto, para Zilberberg, a mistura e a triagem seriam "duas grandes operações da sintaxe extensiva, ou seja, a sintaxe referente aos estados de coisas” (ZILBERBERG, 2011, p. 268). A triagem pressupõe a operação de mistura, isto é, ela "recai sobre misturas que ela desfaz" (ZILBERBERG, 2004, p. 72); já a mistura, como "prática semiótica figural” (ibid., p. 71), em se tratando da Cosmogonia, é resultado da junção não planejada de elementos opostos e aleatórios.
} 
reiterando essas negativas. Com negar, logo define a situação primordial do universo e antecipa o estado da natureza seguinte, pois apontam-se os primeiros elementos que constituem um mundo já enformado. Assim ocorre, por exemplo, nos hexâmetros de número 10 e 11, em que se nega a existência de Titã e Febe, denominação do sol e da lua.

Vale notar, em relação ao décimo primeiro verso das Metamorfoses, um enfoque para o movimento das pontas da Lua, que crescem. O verso, pode-se dizer, focaliza, como uma câmera de cinema em close-up ${ }^{14}$, as pontas da Lua em movimento, efeito que o gerúndio, crescendo, provoca.

Nec noua crescendo reparabat cornua Phoebe ${ }^{15}$,

Nem Febe nova, crescendo, renovava os cornos,

Uma lua crescente, portanto, ganharia corpo a partir da extensão de suas pontas ou chifres. Sugere-se, tendo em vista essa descrição poética - do movimento das pontas lunares (cornua) - um olhar de princípio metonímico, como a câmera de cinema em close-up.

Esse modo de olhar o mundo, por meio de traços típicos dos objetos, marca um estilo poético do narrador das Metamorfoses. Compõe-se, na poesia, um modo sistemático de ver o universo, a partir de características salientes de cada objeto. O poeta faz saltar aos olhos propriedades ora distintas, ora comuns entre seres e coisas. Sobre a poesia narrativa de Ovídio em particular, o formalista russo, Chcheglóv comenta:

Descobre-se a semelhança e a diferença entre os objetos, suas gradações sutis. $\mathrm{O}$ princípio peculiar da mostra permite representar os objetos muito pequenos e muito grandes. Tudo isto pode ser descrito com a ajuda de traços simplíssimos dos objetos, que realizam um milagre: transformam o mundo num sistema (CHCHEGLÓV, 2010, p. 147).

O enunciador das Metamorfoses desenvolve, como se disse, um olhar de tipo ou viés metonímico, ainda mais, geométrico ou espacial, para os fenômenos de transformação. São os chifres da Lua crescente, afinal, que, crescendo, transformam-na em cheia. Da pequena particularidade desse objeto da natureza, suas pontas, narra-se, em um único hexâmetro, uma metamorfose mínima: a mudança de fase da Lua.

A obra constitui-se, portanto, dessas micronarrativas de transformação, cujo encadeamento, muitas vezes surpreendentes - pois, aparentemente, não apresentam relação direta - gera a coerência

\footnotetext{
${ }^{14}$ Close-up: "Tomada em que a câmera, quer distante ou próxima do assunto, focaliza apenas uma parte dele" (HOUAISS, 2001, s. v.).

${ }^{15}$ Nota-se o efeito icônico deste verso a partir do hipérbato.
} 
temática que une os 11.995 hexâmetros, cujo tema mais geral possível é a transformação. $\mathrm{Na}$ Cosmogonia, as transformações voltam-se ao processo criacional, da ordem da púors (phýsis).

Um outro exemplo notável de encadeamento narrativo dos mitos de transformação ocorre quando, após a restauração da humanidade, pós-dilúvio, o poeta conta o nascimento dos seres e, inclusive, das feras, ponte narrativa para a história de Píton, a terrível serpente, aniquilada por Apolo. A isso emenda-se um comentário sobre os jogos píticos para contar que a coroa de louros ainda não existia como prêmio ao vencedor, pois ainda não existia o loureiro. Desse detalhe, da folha de louro da coroa do vencedor dos jogos píticos, estabelece o "gancho" para a história de Febo e Dafne, metamorfoseada em loureiro. Por meio de motivos nada óbvios, estabelece-se o fio condutor das narrativas de transformação.

Ainda em relação à poética da negação, como recurso poético de descrição do Caos, chamam a atenção os hexâmetros de número 8 a 14:

Nec quicquam nisi pondus iners congestaque eodem

Non bene iunctarum discordia semina rerum.

Nullus adhuc mundo praebebat lumina Titan,

Nec noua crescendo reparabat cornua Phoebe,

Nec circumfuso pendebat in aere tellus

Ponderibus librata suis, nec bracchia longo

Margine terrarum porrexerat Amphitrite.

Nada havia, senão um peso inerte e, amontoadas, desunidas sementes de coisas não bem conexas.

Ainda nenhum Titã dava luz ao mundo,

nem Febe nova, crescendo, recuperava os cornos,

nem a terra pendia no ar envolto, com seus próprios pesos equilibrada,

nem Anfitrite estendera os braços pela extensa margem das terras.

Neles, enumeram-se vários elementos que estão em estado de latência - como as sementes, que não encontraram, ainda, seu devido lugar - ou seja, ainda não foram separados, como a terra e o ar que a envolve. Vale observar que, de modo contíguo, as anáforas que iniciam cada verso têm sentido negativo. Destacam-se essas palavras da seguinte forma:

Nec quicquam nisi pondus iners congestaque eodem

Non bene iunctarum discordia semina rerum.

Nullus adhuc mundo praebebat lumina Titan,

Nec noua crescendo reparabat cornua Phoebe,

Nec circumfuso pendebat in aere tellus

Ponderibus librata suis, nec bracchia longo

Margine terrarum porrexerat Amphitrite. 
Ressalta-se que, no verso de número treze, a conjunção nec (nem) aparece exatamente após a cesura, negando a existência de Anfitrite, personificação do mar, como continuidade do efeito de negação e anáfora.

Há, portanto, sete palavras de acepção negativa ao longo de sete versos (em termos sintáticosemânticos, o décimo quarto verso funciona como continuação do segundo hemistíquio do décimo terceiro, logo, a negação dispõe-se também para ele). Essas palavras em destaque reforçam, desse modo, a descrição de um estado inicial do mundo por negação. Os elementos futuros, portanto, ainda inexistem, porque eles se encontram em mistura. O Caos deixa de sê-lo, dando origem às formas, aos elementos e aos primeiros deuses, após a triagem da estrutura constitutiva.

Ainda, no décimo terceiro e no décimo quarto versos,

$$
\begin{aligned}
& \text { (...) nec bracchia longo } \\
& \text { Margine terrarum porrexerat Amphitrite. } \\
& \text { nem os braços estendera, } \\
& \text { pela extensa margem das terras, Anfitrite. }
\end{aligned}
$$

salientam-se os longos braços de Anfitrite, personificação do mar e de sua vasta extensão pelas costas. Pode-se perceber, nessa passagem, a qualidade plástica dos versos de Ovídio, que busca concretizar, na expressão, aquilo que se narra. Ao afirmar que Anfitrite ainda não estendera os seus braços, pela extensa margem das terras, a palavra bracchia (braços) encontra-se o mais distante possível do substantivo próprio Amphitrite (Anfitrite). Esse efeito de prolongamento reforça a extensão dos braços de Anfitrite, que representa a vasta extensão do mar pelos litorais. A combinação da metonímia (bracchia) com o hipérbato (Amphitrite, sujeito no final do verso) produz esse efeito.

Esse fenômeno poético, que consiste em "materializar" os aspectos mais concretos do texto a partir do hipérbato e da metonímia, tendo em vista a configuração espacial das palavras no verso, pode ser mais bem compreendido por meio do conceito de iconicidade:

A figurativização do discurso é, mais exatamente, um processo gradual sustentado de um lado pela iconização, que garante a semelhança com as figuras do mundo sensível e, de outro, pela abstração, que delas se afasta. Essa concepção permite explicitar, de passagem, as categorizações culturais da figuratividade. (...).

A semântica estrutural considera esses diferentes percursos semânticos em termos de "densidade sêmica" mais elevada ou menos: quanto mais elevada ela for, menos o termo afetado por ela admitirá compatibilidades com outros termos e mais o discurso tenderá para a iconicidade; quanto menor a densidade sêmica, mais combinações serão aceitas pelo termo afetado e maior será a tendência à abstração. (...).

Essa elasticidade semântica da figuratividade permite que se fale em uma 
"profundidade" do figurativo, que, longe de se manter na superfície do discurso, como a vestimenta de uma abstração mais profunda, pode ser considerado em si mesmo, por meio dos raciocínios figurativos, por exemplo, como um dado primário da linguagem (BERTRAND, 2003, p. 231).

Em suma, no verso sobre Anfitrite e seus braços que se estendem longamente pelos litorais do mundo, Ovídio planeja um hexâmetro em que se dispõem dois substantivos, bracchia e Amphitrite, o mais distante possível, tanto do ponto de vista sintático-semântico como da tensão admitida pelo verso. Essa dimensão plástica do verso, por certo, está profundamente associada a um nível mais denso do discurso figurativo.

Parece que há, em Ovídio, uma predileção em focalizar particularidades geométricas dos objetos - em close-up, como os chifres da Lua - e em planejar a espacialidade do verso - como nos hexâmetros treze e quatorze. Semelhante efeito também é possível perceber no quinto hexâmetro da obra:

Ante mare et terras et, quod tegit omnia, caelum

Antes do mar e das terras e do céu, que cobre tudo,

em que se localiza o tempo inicial do mundo, anterior aos elementos básicos. Nesse período, tudo se mistura. Esse efeito de caos pode ser percebido também na construção plástica do verso, para além do conteúdo, por meio do polissíndeto, explicitado em seguida.

Assim, em relação à construção da imagem de Caos como um estado primordial em que tudo se encontra amalgamado e indistinto, é possível notar uma disposição frasal, em um nível mais concreto da palavra, que reforça, de modo mais expressivo, essa imagem. Pode-se perceber, no primeiro verso do excerto em destaque, por meio do polissíndeto, isto é, da repetição da conjunção et, um efeito de soma ou concomitância: no plano do conteúdo, todos os elementos enumerados não se encontram separados, mas ainda estariam amontoados numa mesma substância, o próprio Caos, que é a mistura; no plano da expressão, o polissíndeto sugere, pois, esse efeito de soma e mistura.

Ademais, além dos dois et explícitos como enumeração, há uma sugestão sonora do verso em que se reverbera a conjunção aditiva $e t$, tendo em vista os fonemas /e/ e /t/. Essa imitação sugestiva suporta, em um nível mais concreto, a construção imagética da figura de Caos, entidade em que se somam todos os elementos primordiais, de modo simultâneo e sem ordenação.

Vale perceber que, ao longo do verso, as conjunções embaralham-se, como se não houvesse ainda disposição. Assim, no primeiro verso desse episódio, sublinham-se os sons assonantes e aliterantes que reforçam a presença da conjunção aditiva, corroborando o efeito de simultaneidade e de falta de distinção, devido à mistura, marcas próprias do Caos: 


\section{Ante mare $\frown$ et terras et, quod tegit_omnia, caelum}

Antes do mar e das terras e do céu, que cobre tudo,

As conjunções et, portanto, bem como o baralhamento dos fonemas (et, te, it), haja vista também a sinalefa em mare e et e o sândi em tegit omnia, sugerem, sensorialmente, o estado inicial da natureza, cujo único rosto era o de Caos, isto é, o princípio de indistinção.

Ainda em relação aos aspectos mais concretos desse verso, vale destacar o posicionamento do pronome relativo "que" (quod) e do substantivo céu (caelum). Na passagem, o céu tem como natureza cobrir todas as coisas (tegit omnia). Ao dizer que o céu tudo cobre, no segundo hemistíquio, após a cesura, o verbo e o acusativo plural (tegit omnia) estão, espacialmente, circunscritos entre a conjunção et e o próprio substantivo céu, como se ele, de fato, “cobrisse” todas as coisas. Há uma sugestão de que caelum, portanto, compreende a subordinada adjetiva, que contém a palavra omnia (todas as coisas), sugerindo um movimento.

\section{Āntě mălr(e)_ēt tērlrās ēt, I quōd těgĭt I ōmnŭă, I cāelŭm}

Destaca-se que a cesura, logo após a sílaba -ras (de terras) no terceiro pé, reforça essa sugestão espacial, pois ela separa os outros elementos (mare / terras), no primeiro hemistíquio, do substantivo caelum no segundo e enfatiza o céu "cobrindo" omnia. Dessa forma, terra e mar estão mais próximas do que o céu, que dista de tudo. Assim, as palavras mare e terras estão próximas e caelum, longe delas, como se a ordenação frasal sugerisse também uma disposição mítico-geográfica dos elementos. Ressalta-se que a sinalefa do segundo pé reforça essa leitura, pois amplia a ideia de mar e terra estarem misturados.

Ademais, pode-se estender essa sugestão, a do céu velando tudo, ao verso todo, tendo em vista o distanciamento espacial entre a preposição ante e o termo que a ela se liga, caelum. Ante caelum é um sintagma temporal, haja vista a relação sintática e coesiva entre os termos. Apesar da conexão entre eles, ante e caelum estão dispostos no hexâmetro o mais distante possível um do outro, conscientemente separados pelo hipérbato, o que demonstra uma semelhança ou homologia entre conteúdo e expressão. A extensão do céu, que tudo cobre, é também, pois, a extensão do próprio verso.

Tendo em vista o distanciamento entre o latim clássico e a contemporaneidade, bem como a dificuldade em recuperar sensorialmente o que seria, de fato, a prosódia de um hexâmetro, propõese, abaixo, um esquema que procura demonstrar visualmente a sugestão imitativa de caelum (o céu) cobrindo o verso. É uma tentativa artificial de propor um "movimento de leitura”, considerando a suspensão morfossintática que as palavras ante e quod obrigariam o ouvinte romano a fazer, até completar o sentido da frase, em caelum. Assim, em relação a esse efeito expressivo, sugere-se: 


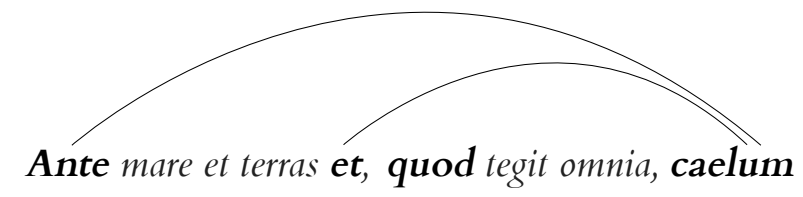

Nesse quinto verso, em síntese, a ordem das palavras eleva a um grau mais profundo o discurso figurativo, em que os elementos que sucedem o estágio inicial do mundo, o Caos, ainda inexistem, como a água, o ar e a terra. Ao narrar a mistura de todos os elementos, amalgamados em uma massa sem forma nem organização, repete-se a conjunção aditiva et, sustentando a ideia de simultaneidade, e embaralha-a, propiciando um efeito de indistinção. Ademais, ao afirmar em uma subordinada que o céu tudo cobre, espacialmente tem-se o efeito concreto disso.

Já nos hexâmetros de número 18 a 20,

Obstabatque aliis aliud, quia corpore in uno

Frigida pugnabant calidis, umentia siccis,

Mollia cum duris, sine pondere habentia pondus.

e uma coisa fazia obstáculo a outra, porque, em um mesmo corpo,

as frias temperaturas lutavam contra as quentes, as coisas úmidas, com as secas,

as moles, com as duras, o peso com as sem peso,

tematiza-se a briga entre os elementos da natureza. Devido à falta de organização entre eles, a forma de nada se mantinha (nulli sua forma manebat). Ou seja, não era possível, por causa da contenda, gerar vida ou estabelecer função. Um elemento, pois, impede o outro de surgir. Configura-se, assim, o Caos: um estado de luta interna.

O poeta seleciona, como enumeração, termos antitéticos. Opõem-se, pois, o frio e o quente, o úmido e o seco, o mole e o duro e, por fim, o pesado e o não pesado. Ou seja, são propriedades físicas gerais e primárias que passarão a constituir todos os outros elementos, sendo base das transformações. Por exemplo, nos hexâmetros 348 a 415, ao tratar do mito de Deucalião e Pirra, tem destaque a cena em que as pedras, de substância dura, amolecem, após terem sido arremessadas às costas para dar forma a novos homens e mulheres. A transferência de natureza ou mudanças de estado, seja duro ou mole, seja quente ou frio, por exemplo, é característica básica de muitas metamorfoses. Mudam-se as formas, alteram-se, também, os estados físicos:

Vê-se pelos exemplos referidos que os objetos são caracterizados por Ovídio com a ajuda de um conjunto de noções físicas e espaciais abstratas, como por exemplo, a curvatura, o vazio, a dureza, a liquidez, a longuidão etc. Vê-se que este conjunto de noções é limitado em comparação com a variedade dos objetos do mundo real, 
que eles descrevem, pelo fato de que os mesmos epítetos se repetem na nomeação de diferentes objetos. Muitos objetos até bem diferentes, objetos e partes destes, recebem o mesmo traço e são assim justapostos. Por exemplo, a qualidade da curvatura, da forma oblíqua, torna possível justapor objetos como a foice, as costas do golfinho, o navio, o corno do carneiro e até a superfície do mar durante a tempestade (curvum circumstetit aequor) (CHCHEGLÓV, 2010, p. 144).

Assim, nas Metamorfoses, o enunciador observa, com enorme precisão, a propriedade ou natureza das coisas e dos seres. Esse olhar torna-se um sistema, que concebe o mundo por sua lógica, dando-lhe sentido. O estilo ovidiano interessa-se pela geometria das formas, chamando a atenção do leitor para qualidades não comumente percebidas. Ovídio, portanto, arquiteta um estilo que visa a desautomatizar as formas da natureza, ora emparelhando, ora diferenciando, ora encontrando similitudes, ora exaltando dessemelhanças. Estabelece-se, pois, um sistema poético do mundo ou, ainda mais, da constituição orgânica dele.

O princípio cosmogônico, qual seja, a mistura dos elementos e a sua triagem, aparece tanto no início do episódio cosmogônico quanto no final, após o dilúvio e a restauração da humanidade. Sugere-se que Ovídio, nos últimos hexâmetros (430-433) sobre a Cosmogonia, queira fazer uma conclusão, extremamente lacônica, da equação do mundo físico, com ênfase na procriação. Isto é, ele estabelece uma sentença que define o mecanismo mais primordial de funcionamento do universo físico associado à criação: o equilíbrio entre elementos opostos. Esse recurso demonstra também o projeto textual rigoroso de Ovídio, que concebe o seu carmen perpetuum, em que há uma profunda soliedaridade entre as narrativas, do primeiro ao último verso da obra inteira.

Como recurso didático, pois, ele retoma o pensamento inicial nos primeiros hexâmetros, sobre a origem do mundo, e conclui, no final do episódio inteiro, de modo "científico":

\footnotetext{
Quippe ubi temperiem sumpsere umorque calorque,

Concipiunt et ab his oriuntur cuncta duobus;

Cumque sit ignisi aquae pugnax, uapor umidus omnes

Res creat et discors concordia fetibus apta est.
}

Naturalmente, após a umidade e o calor terem-se misturado, concebem e, a partir da união dos dois, tudo se origina.

Embora o fogo, em todas as vezes, seja o combatente da água, o úmido vapor cria todas as coisas, e a concórdia discordante é adequada à procriação.

A fórmula do mundo pode ser sintetizada, mais especificamente, em parte do hexâmetro 433: "discors concordia fetibus apta est". Trata-se, portanto, do resumo do mecanismo da vida, cujo fundamento está na aproximação equilibrada dos elementos já distintos, após triagem. A procriação, logo, não se encontra nos opostos, mas na união deles, com vista ao equilíbrio. 
Essa síntese, aponta Anderson, foi utilizada por Horácio, como fundamento do universo físico, assim como Manílio e Lucrécio também se valeram desse pensamento. Ovídio focaliza, particularmente, os elementos água e fogo que, em simbiose, propiciam a vida, sob forma de vapor. É o que comenta Anderson, ao analisar a passagem:

"quippe ubi: commentators like Bömer and Lee focus on quippe alone (which Ovid employs only in the Met, and Tristia). However, it is the two words that define the style here, for they are characteristic of Lucretius and the "natural science" that Ovid affects in this long simile. (Cf. Lucr. 1. 167, 182, 242, etc.) temperiem sumpsere: the noun is an Augustan formation, to create a metrically usable equivalente for such words as temperatio. Ovid uses it before at 51. for the importance of moisture and heat, $c f .417-18$. concipiunt 431: pregnancy occurs merely from the mixture of hot and cold, which then generates every animate thing. aquae: dative with pugnax, a bold poetic syntax that Ovid may well have invented here, later to be used by Silver Latin writers. vapor umidus: the combination of heat and moisture. discors concordia 433: this phrase had already been used by Horace of the operation of the physical universe in Epist. 1.12.19, reversing the words to make a hexameter ending; and Manilius has Horace's phrase in 1.142. Ovid has ingeniously transferred the sense specifically to the creative opposition of moist and hot. fetibus apta: "fosters the creation of living things" (grifos nossos) (OVID, 1998, p. 188). ${ }^{16}$

Assim, após a triagem dos elementos já distintos, a vida surge com a combinação adequada deles. Não há mais "luta” entre eles, senão na intensidade adequada à procriação. A imagem emblemática que Ovídio constrói, como figura que melhor expressa a ideia de fonte de vida é o vapor, um estado de intensidade equilibrada entre água e fogo, elementos antagônicos.

Em resumo, os últimos versos do episódio Cosmogônico (v. 430 a 433) resgatam o episódio inicial em análise e demonstram um projeto textual coeso, que retoma a ideia central e estabelece uma síntese. A vida nasce do equilíbrio entre elementos opostos, que, separados, após triagem, "não lutam" mas combinam-se na devida intensidade.

Por fim, em relação aos versos iniciais do episódio cosmogônico, vale ressaltar que o estado de caos ressurge sempre que as substâncias e os seres não estão mais em ordem ou no devido lugar, como se pode perceber, mais adiante, ainda no Livro I (hex. 253-312), com o dilúvio, quando água, ar

\footnotetext{
16 quippe ubi: comentadores como Bömer e Lee concentram-se apenas em quippe (que Ovídio emprega apenas nas Met. e Tristia). No entanto, são as duas palavras que definem o estilo aqui, pois são características de Lucrécio e da "ciência natural" que Ovídio emprega nesse longo símile. (Ver Lucr. 1. 167, 182, 242, etc.) temperiem sumpsere: o substantivo é uma formação da época de Augusto, para criar um equivalente metricamente utilizável para palavras como temperatio. Ovídio usa-o anteriormente no v. 51, para designar a importância da umidade e do calor, ver 417-18. concipiunt 431: a gravidez ocorre meramente da mistura de calor e frio, que então gera coisas animadas. aquae: dativo com pugnax, uma ousada sintaxe poética que Ovídio pode muito bem ter inventado aqui, e que será mais tarde usada por escritores latinos da "época de prata”. vapor umidus: combinação de calor e umidade. discors concordia 433: esta frase já havia sido utilizada por Horácio a respeito da operação do universo físico em sua Arte Poética 1.12.19, revertendo as palavras para fazer um final hexamétrico; e Manílio mantém a frase de Horácio em 1.142. De modo engenhoso, Ovídio transferiu o sentido especificamente para a oposição de umidade e calor no ato criativo. fetibus apta: "promove a criação de seres vivos".
} 
e terra voltam a misturar-se, por ordem de Júpiter, e quase tudo é destruído, regressando a um estado semelhante ao Caos. No dilúvio, seres terrestres dividem espaço com os seres aquáticos. Ou seja, há, novamente, uma mistura. O dilúvio, portanto, seria um retorno parcial ao Caos.

À guisa de ilustração, no primeiro hemistíquio do hexâmetro 304,

Nat lupus inter oues

O lobo nada entre as ovelhas,

Ovídio estabelece uma imagem emblemática do retorno gradativo do mundo a um estado de Caos. À medida que as distinções deixam de existir, o mundo vai se tornando primordial. Nesse hemistíquio, lobo e ovelhas igualam-se, não mais se distinguem, tendo o mundo se transformado, em regresso à mistura.

Assim, Caos seria a substância máxima ou total que contém todo o potencial de vida do universo, ou seja, as sementes do mundo, mas que se encontram inertes, sem função, porque não houve ainda sua devida disposição no mundo, não houve sua organização pelo artista do mundo, o opifex rerum. O universo físico, composto essencialmente de ar, terra, fogo e água, começa a tomar forma a partir do momento em que se separam os elementos dessa massa inerte e as propriedades físicas de cada um são estabelecidas.

Observou-se, portanto, a homologia entre plano de conteúdo e de expressão, tendo em vista a disposição das palavras no verso e o uso de figuras de linguagem como o hipérbato, que sugere a iconicidade, o polissíndeto, cujo efeito é reforçar sensorialmente o Caos como mistura, e a anáfora, fundamental à poética da negação, recurso de descrição do mundo primordial.

Desse modo, o que é substância ganha forma com a triagem; aquilo que é Caos torna-se mundo enformado com função, lugar e nome. A dicotomia mistura e triagem, portanto, é a operação cosmogônica primordial que estabelece, respectivamente, a substância e a forma, o Caos e o mundo.

\section{Referências bibliográficas:}

BERTRAND, Denis. Caminhos da semiótica literária. Tradução Grupo Casa. Bauru-SP: Edusc, 2003.

CHCHEGLÓV, I. K. Algumas características da estrutura de As Metamorfoses de Ovídio. In: SCHNAIDERMAN, Bóris (Org.). Semiótica russa. Tradução de Aurora F. Bernardini et al. São Paulo: Perspectiva, 2010, pp. 139-157. 
COMMELIN, P. Mitologia Grega e Romana. Trad. de Thomaz Lopes. Rio de Janeiro: Ediouro, [19-].

CONTE, Gian Biagio. Latin Literature: a History. Translated by Joseph B. Solodow. Baltimore: The Johns Hopkins University Press, 1999.

HOUAISS, Antônio \& VILLAR, M. de Salles. Dicionário Houaiss da língua portuguesa. Rio de Janeiro: Objetiva, 2001.

HOWATSON, M.C. The Oxford Companion to Classical Literature. New York: Oxford Press, 2005.

LUCRÉCIO. Da natureza. São Paulo: Abril Cultural, Coleção Os Pensadores, 1985.

OVID. Ovid's Metamorphoses. Books 1-5. Edited, with introduction and Commentary, by William S. Anderson. Oklahoma: University of Oklahoma Press, 1998.

OVIDE. Les Métamorphoses. Tome I (I-V). Text établi et traduit par Georges Lafaye. Paris: Les Belles Lettres, 1928.

OVÍDIO. Metamorfoses. Tradução de Bocage; introdução de João Angelo Oliva Neto. São Paulo: Hedra, 2000.

SANTOS, E. C. P. dos. O mito da criação: o conceito de Cosmogonia nas Metamorfoses de Ovídio. [s. d.]. Disponível em: <http://www.jayrus.art.br/Apostilas/LitLatina/Elaine_C._Prado_dos_ Santos.pdf>. Acessado em: 3 ago. 2018.

ZILBERBERG, Claude. As condições semióticas da mestiçagem. Tradução de Ivã Carlos Lopes e Luiz Tatit. In: CAÑIZAL, Eduardo Peñuela; CAETANO, Kati Eliana (Org.). O olhar à deriva: mídia, significação e cultura. São Paulo: Annablume, 2004, pp. 69-101.

ZILBERBERG, Claude. Elementos de Semiótica Tensiva. Tradução de Ivã Carlos Lopes, Luiz Tatit e Waldir Beividas. São Paulo: Ateliê Editorial, 2011.

ZILBERBERG, Claude. Raison et poétique du sens. Paris: Presses Universitaires de France, 1988.

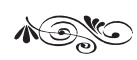

